\title{
el poder desde la perspectiva de foucault y la práctica de filosofía con niños en la escuela.
}

ana corina salas ${ }^{1}$ universidade do estado do rio de janeiro, rio de janeiro, rio de janeiro, brasil orcid id: https:/ / orcid.org/0000-0003-0239-0420

\section{resumen}

Entendemos que la práctica de Filosofía con Niños, propuesta por Walter Kohan, dentro de la escuela, nos invita a pensarnos y en ese acto reflexivo saber lo que somos -y estamos siendo-, lo que queremos y no queremos ser, dándonos la posibilidad de transformarnos. Para transformarnos, dice este filósofo, es necesario abandonar los dispositivos que nos llevan a ser eso que somos. Ahora, ¿Qué somos? ¿Qué somos en cuanto docentes? ¿Qué somos en cuanto alumnos? ¿Qué dispositivos nos llevan a ser eso que somos? Para pensar estas preguntas analizaremos, con Michel Foucault, la escuela, institución donde se desarrolla la práctica de Filosofía con Niños, con el fin de entender las relaciones de poder que existen en este recinto. Cómo, a raíz de ellas, se moldea y se define qué es ser docente y ser alumno. Para ello, haremos una introducción al pensamiento foucaultiano y analizaremos qué es el poder, el poder pastoral, el poder disciplinario y la resistencia que da forma, según el filósofo francés, a este recinto educativo. Asimismo, presentaremos la propuesta de Filosofía con Niños y expondremos la posibilidad y necesidad, presentada por Kohan, de que la filosofía ejercida dentro de la escuela reflexione en torno a las prácticas coercitivas de poder vivas en el salón de clases y desde ahí, pueda crear y abrirse a otras formas de relación. Finalmente argumentamos que la práctica de Filosofía con Niños, se constituye, en los términos de Foucault, en cuanto una práctica de resistencia en la escuela.

palabras clave: poder; escuela; foucault; filosofía con niños; resistencia.

\section{o poder a partir da perspectiva de foucault e a prática de filosofia com crianças na escola.}

\section{resumo}

Entendemos que a prática da Filosofia com Crianças na escola, proposta por Walter Kohan, convida-nos a pensar sobre nós mesmos e nesse ato reflexivo a saber o que somos - e estamos sendo -, o que queremos e não queremos ser, nos dando a possibilidade de transformar-nos. Para nos transformarmos, diz este filósofo, é necessário abandonar os dispositivos que nos levam a ser o que somos. Agora, o que somos? O que somos nós como docentes? O que somos nós como alunos? Que dispositivos nos levam a ser o que somos? Para pensar essas questões, iremos analisar, com Michel Foucault, a escola, instituição onde se desenvolve a prática da Filosofia com Crianças, a fim de compreender as relações de poder que existem neste recinto. Como, a partir delas, se forma e se define o que é ser docente e ser aluno. Para isso, faremos uma introdução ao pensamento foucaultiano e analisaremos o que é o poder, o poder pastoral, o poder disciplinar e a resistência que configura, segundo o filósofo francês, este recinto educacional. Da mesma forma, apresentaremos a proposta da Filosofia com Crianças e exporemos a possibilidade e necessidade, apresentada por Kohan, de a filosofia exercida na escola refletir sobre as práticas coercitivas de poder presentes na sala de aula e, a partir daí, criar e abrir-se a outras formas de relacionamento. Por fim, argumentamos que a prática da Filosofia com Crianças se constitui, nos termos de Foucault, como uma prática de resistência na escola.

\footnotetext{
${ }^{1}$ Email: coricori18@gmail.com
} 
el poder desde la perspectiva de Foucault y la práctica de filosofía con niños en la escuela.

palavras-chave: poder; escola; foucault; filosofia com crianças; resistência.

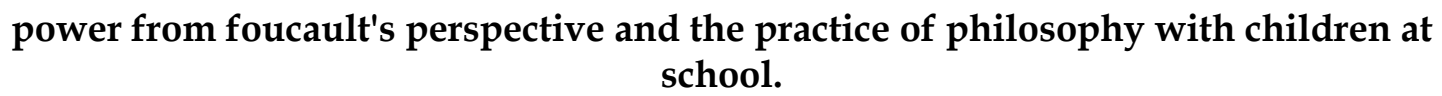
school.

\begin{abstract}
We understand that the practice of Philosophy with Children within the school, proposed by Walter Kohan, invites practitioners to think about themselves and, in that reflective act, to know what they are - and what they are being -, what they want and do not want to be, giving themselves the possibility of self-transformation. In order to transform ourselves, says this philosopher, it is necessary to abandon the devices that lead us to be what we are. But, what are we? What are we as teachers? What are we as students? What devices lead us to be what we are? To think about these questions we analyze, with Michel Foucault, the school, an institution where the practice of Philosophy with Children takes place, in order to understand the power relations that exist in this space. We will understand how this power relations shape and define what it is to be a teacher and to be a student. To do this, we start with an introduction to Foucault's thought, analyzing what is power, pastoral power, disciplinary power and resistance that, according to the French philosopher, shapes school as an educational locus. Likewise, we will present the Philosophy with Children proposal and expose the possibility and need, stated by Kohan, for philosophy (as an exercise within the school) to reflect on the coercive practices of power experienced in the classroom and, from there, to create and openness to other forms of relationship between those who inhabit it. Finally, we argue that the practice of Philosophy with Children constitutes, in Foucault's terms, a practice of resistance within schools.
\end{abstract}

keywords: power; school; foucault; philosophy with children; resistance. 
el poder desde la perspectiva de foucault y

la práctica de filosofía con niños en la escuela.

\section{introdução}

Según Miguel Morey, siguiendo a Deleuze, el pensamiento de Foucault (1926-1984), se suele organizar desde tres interrogantes: “¿Qué sé?, ¿Qué puedo?, ¿Qué soy?" (1987, p. 17). La primera interrogante ¿Qué sé? -¿Qué es el saber?-, están vinculados a los estudios arqueológicos que van de la Historia de la locura (1961) hasta La arqueología del saber (1969). La segunda ¿Qué puedo? -¿Qué es el poder?periodo denominado genealógico. Este período incluye Vigilar y castigar (1975), y los libros desde El orden del discurso (1970) hasta el primer volumen de la Historia de la sexualidad -La voluntad de saber-(1976). La tercera pregunta ¿Qué soy?, refiere los estudios sobre ética vinculados al segundo y tercer volumen de Historia de la sexualidad, El uso de los placeres (1984) y El cuidado de sí (1984) (Giraldo, 2006).

Estas preguntas, hechas en primera persona por Foucault nos transmiten que su vida se desarrolló como una práctica filosófica, donde el pensamiento y la acción conformaron una unidad. El conjunto de sus obras trabajadas en el curso de tantos años no remiten

(...) a un último dominio dentro de cuyos límites reside la verdad, sino que por el contrario abren una dispersión interrogativa a la que no subyace sino un ¿qué...? como expresión de un asombro y génesis de todo filosofar, que en su intento por determinar, en su actualidad, el pasar de las cosas que (nos) pasan, parece devolver mediante este gesto el pensar contemporáneo a sus arcaicos orígenes griegos, y lo revitalizan mediante la repetición de ese momento matinal (Morey, 1987, p. 17).

En otras palabras, si bien se ha intentado dar un orden al pensamiento de Foucault mediante la división de estos tres momentos, se hace imposible reducirlo a un principio último, a un fundamento de validez universal. La pregunta por el ¿Qué...? en este filósofo francés es realizada desde el asombro y la posibilidad de pensar una y otra vez sobre los asuntos que conciernen a los seres humanos sin límites, sin fundamentos últimos, sin determinaciones ${ }^{2}$.

\footnotetext{
2 Foucault se escurre enfáticamente de cualquier intento por determinar su pensamiento, admite escribir para perder el rostro, y se burla de quién quiere encontrarlo diciendo: "No, no, no estoy donde ustedes tratan de descubrirme sino aquí desde donde los miro riendo" (Foucault, 2008, p. 30).
} 
el poder desde la perspectiva de foucault y la práctica de filosofía con niños en la escuela.

Para efectos de este artículo nos centraremos en el periodo genealógico. En ella, Foucault, quiebra el modo en cómo hasta ese momento se estaba entendiendo el poder. El poder se concebía como la fuerza que provenía del Rey o del Estado que subyugaba e inmovilizaba a los individuos. Foucault se distancia de esta visión y propone entender el poder como una fuerza generada por los mismos sujetos ${ }^{3}$ mediante la interacción de sus capacidades o habilidades. (Giraldo, 2006, p. 106).

Foucault realiza un análisis histórico del poder, pasando por el poder pastoral, llega al poder disciplinario y denuncia que es este poder el que caracteriza ciertas instituciones como los hospitales, manicomios, cárceles y escuelas. En este artículo nos centramos en las relaciones de poder presentes en la escuela, lugar en el que se realiza la experiencia de Filosofía con Niños propuesta por el filósofo Walter Kohan.

Kohan y Waksman (2005) en el libro Filosofía con Niños: aportes para el trabajo en clases, plantean que uno de los sentidos que fundamenta la experiencia de Filosofía con Niños es afirmar la autonomía del individuo. La filosofía es para ellos "un ejercicio que amplía la subjetividad, que nos permite pensar y ser de otro modo del que lo estamos haciendo, que afirma, al fin, la autonomía individual y colectiva, el darse a uno mismo la propia norma" (Kohan; Waskman, 2005, p. 77). La filosofía dentro de la escuela invita al individuo a pensar-se y en ese acto reflexivo saber lo que es -y está siendo-, lo que quiere y no quiere ser. En otras palabras, por medio del hacer filosófico ejercemos nuestra capacidad en tanto seres humanos de definir y hacernos responsables por lo que somos y queremos ser; es no dejar en manos de

\footnotetext{
${ }^{3}$ La palabra "sujeto", en Foucault, guarda dos significados: “(...) sujeto a otro por control y dependencia y sujeto como constreñido a su propia identidad, a la conciencia y a su propio autoconocimiento. Ambos significados sugieren una forma de poder que sojuzga y constituye al sujeto" (Foucault, 1982, p. 4). De tal modo, que cuando hablamos del ser humano en tanto sujeto, nos referimos, siguiendo al autor, a dos formas de estar sujetados: al control y obediencia de otro individuo y a las prácticas sociales a través de las cuales se tiene conocimiento de sí.Para ejemplificar esto, podemos usar el siguiente diálogo: "-Madre: Hija, pero habla con la maestra, dile que no entiendes. -Hija: ¿Estás loca mamá? Ella es peligrosa: ella es una maestra y yo una alumna." La hija, podemos decir, niega la opción propuesta por su madre de conversar con la maestra, porque para ella, entre la figura de alumna que ella representa y la de su maestra no es posible un diálogo. No pensamos que éste sea un caso generalizable, simplemente queremos mostrar con esta conversación entre una madre y su hija, cómo la institución y la relación con las otras, pueden ir sujetando al ser humano.
} 
otros la creación de las normas que guían nuestra vida y la de la comunidad de la que formamos parte.

La práctica de Filosofía con Niños en la escuela nos da la posibilidad, a docentes y alumnos, de ser de otros modos. En este sentido Kohan dice, fuertemente influenciado por el autor francés que aquí trabajaremos: “(...) Si queremos transformar lo que somos, es preciso abandonar los dispositivos que nos llevan a ser lo que somos" (Kohan, 2002, p. 62). Ahora, vale preguntarnos: ¿Qué somos? ¿Qué somos en cuanto docente? ¿Qué somos en cuanto alumnos? ¿Qué dispositivos nos llevan a ser eso que somos? Entiendo que es necesario mantener estas preguntas abiertas, buscar respuestas posibles, para después, si así lo deseamos, transformar eso que somos.

En las siguientes líneas, nos detenemos en el análisis histórico del poder hecho por Michel Foucault, y en específico en el poder pastoral y disciplinario, que atraviesa según él la relación docente- alumno. Lo que queremos es continuar pensando que somos en cuanto docente y alumno, qué dispositivos nos hacen ser así. Hacemos también este estudio movilizados por otra pregunta: ¿Es posible la práctica de Filosofía con Niños (¡Ser de otros modos!), en una institución escolar definida, según Foucault, por su poder disciplinario?

\section{análisis histórico del poder}

¿Qué es el poder?

Sí leemos la conferencia Omnes Et Singulatim: Hacia una crítica del poder de la razón política, dada por Foucault en 1979, encontramos que:

El rasgo distintivo del poder es que algunos hombres pueden, más o menos, determinar por completo la conducta de otros hombres, pero jamás de manera exhaustiva o coercitiva. Un hombre encadenado y azotado se encuentra sometido a la fuerza que se ejerce sobre él. Pero no al poder. Pero si se consigue que hable, cuando su único recurso habría sido el de conseguir sujetar su lengua, prefiriendo la muerte, es que se le ha obligado a comportarse de una cierta manera. Su libertad ha sido sometida al poder. Ha sido sometido al gobierno. Si un individuo es capaz de permanecer libre, por muy limitada que sea su libertad, el poder puede someterle al gobierno (Foucault, 1990, p. 138). 
el poder desde la perspectiva de foucault y la práctica de filosofía con niños en la escuela.

El poder, siguiendo la idea foucaultiana, pretende determinar las posibles acciones de otros individuos, restringir lo que los sujetos pueden o no. Gobernarlos. Lo que no implica que el sujeto no pueda escoger reaccionar de una forma diferente a la pretendida por el poder. Ante la exigencia de hablar, por ejemplo, el sujeto puede elegir morir.

Distingue en tal sentido Foucault, entre una situación de poder y una situación de dominación. Cuando el individuo, se encuentra atado de pies y manos sin ninguna opción, dice Foucault, está el individuo en un estado de dominación. Sí por el contrario tiene éste opciones entre las cuales escoger, está inmerso el individuo en una relación de poder. Lo que diferencia una situación de otra, es la libertad.

El individuo que está dominado, al no poseer la posibilidad de actuar de otro modo, no posee ningún tipo de libertad. En cambio, el que está en una situación de poder, al tener opciones -aun siendo reducidas- entre las cuales elegir, conserva su libertad y autonomía. Lo que el poder busca, en este sentido, es determinar las acciones de los individuos, coartar la autonomía de los mismos. Por tanto, el poder se ejerce sobre individuos libres.

Se entiende en Foucault por sujetos o colectivos libres, aquella o aquellas personas que, como dice Castro “(...) tienen ante ellos un campo de posibilidad en el que pueden darse muchas conductas, muchas reacciones y diferentes modos de comportamiento" (2004, p. 414). La libertad, en Foucault, apegándonos a la idea de Castro, es la posibilidad de decidir qué camino tomar.

También indica Foucault que el poder cumple con ciertas características. “(...) No es algo que se adquiera, arranque o comparta, algo que se conserve o se deje escapar; el poder se ejerce a partir de innumerables puntos, y en el juego de relaciones móviles y no igualitarias" (2006, p. 99). Siguiendo al autor, el poder viene de todos los lugares, no se encuentra en una zona determinada en forma inmóvil.

De tal modo, que el poder no está en el rey, jefe, maestro o en la persona que representa al Estado. Tampoco está en el súbdito, empleado, alumno, individuos, ciudadanos. No se sintetiza en la relación vertical dominado-dominador. Sino que son fuerzas en constante movimiento, que entraman relaciones desiguales. 
El poder, también, es omnipresente, “(...) no porque tenga el privilegio de reagruparlo todo bajo su invencible unidad, sino porque se está produciendo a cada instante" (Foucault, 2006, p. 98). En cada tiempo, en cada espacio, el poder está ahí, generándose entre nosotros, nosotros lo producimos. Se trata así de una malla interactiva de fabricación de poder en el juego de las relaciones humanas.

El poder, en este sentido, son relaciones, que “(...) no están en posición de exterioridad respecto de otros tipos de relaciones (procesos económicos, relaciones de conocimiento, relaciones sexuales), sino que son inmanentes (a ellas)" (Foucault, 2006, p. 99). En consecuencia, no se puede separar el poder de ningún vínculo entre humanos, pues le es inherente. Va emergiendo de las prácticas cotidianas de socialización creadas por los propios individuos.

(...) Una de las primeras cosas que debe comprenderse -dice Foucault- es que el poder no está localizado en el aparato de Estado, y que nada cambiará en la sociedad si no se transforman los mecanismos de poder que funcionan fuera de los aparatos de Estado, por debajo de ellos, a su lado, de una manera mucho más minuciosa, cotidiana (2009, p. 108).

Lo que entendemos a partir de lo dicho por Foucault es que el poder y todo lo que implica acontece y adquiere movilidad diariamente entre nosotros. No se trata de una fuerza metafísica que responde a circunstancias ajenas a lo humano. Por el contrario, el poder pertenece exclusivamente al campo humano. En consecuencia, para cambiar ciertas instituciones en la sociedad es necesario modificar los micros mecanismos de poder, los que generan los sujetos. En otras palabras, sólo los individuos pueden transformar las instituciones sociales alterando las formas de poder que determinan su socialización.

\section{el poder pastoral y el estado moderno}

Al trasladar este análisis del poder, al plano histórico, Foucault, nos muestra que las relaciones de gobierno que caracterizan la modernidad y por ende, la relación del docente con sus alumnos, tiene la impronta del poder pastoral.

Por poder pastoral, se refiere Foucault, a la analogía entre el pastor y la divinidad, rey o jefe, presente tanto en las antiguas sociedades orientales, Egipto, 
el poder desde la perspectiva de foucault y la práctica de filosofía con niños en la escuela.

Asiria, Judea ${ }^{4}$ y en sociedades occidentales como las de tradición hebrea y cristiana. En la cultura griega tal semejanza, para el autor de Tecnologías del yo, no es característica.

$\mathrm{Al}$ argüir Foucault las razones por las cuales considera que la alegoría del Dios y/o rey como pastor no define la cultura griega, deja de lado los textos homéricos y se centra en los textos políticos del pensamiento griego, mostrando, que ni en Aristóteles, Isócrates, Demóstenes, se describe esta relación (Foucault, 1990). Será Platón quien vincule en los diálogos como el Critias, La República, y Las Leyes, la figura del magistrado con la figura de aquel que guía al rebaño (Foucault, 1990). Pero en estos textos el tema central es otro, no el del poder pastoral. Es sólo en el Político donde Platón aborda la pregunta: “¿Puede definirse como una especie de pastor a aquel que en la ciudad toma las decisiones y manda?" (Foucault, 1990, p. 106).

El conocido diálogo, por medio del método de la división, define en un primer momento al jefe político como pastor de hombres, pero tal conclusión genera insatisfacción. Porque, la función del político, no es la de ser la cabeza del rebaño, dar de comer, criar o vigilar el apareamiento, como en el caso del pastor, sino que “(...) consiste en formar y asegurar la unidad de la ciudad" (Foucault, 1999, p. 110). Él es un tejedor, tiene que trenzar y cuidar del entramado social. Dios o los dioses, tampoco serán asociados a esta imagen pastoril, porque como se dirá en el diálogo, escribe Foucault, "Al tener a la divinidad como pastor, los hombres no necesitaban constitución política" (Foucault, 1999, p. 109), esta idea de una sociedad sin leyes, era para los griegos impensable. Es por tanto, iniciado de nuevo el proceso, reconociendo al médico, al campesino, al titiritero y al pedagogo como pastores (Foucault, 1990).

Es así, como Foucault rastreando los indicios del poder pastoral en los griegos, dice que dentro de esta cultura no debió ser ésta una analogía común porque no figura de un modo constante en los textos políticos y donde adquiere más fuerza es claramente diferenciada de la imagen del rey o Dios.

\footnotetext{
${ }^{4}$ Se tiene referencia, por ejemplo, de analogías hechas entre la figura del faraón, el monarca
} babilónico con la del pastor de ovejas (Foucault, 1990). 
En los hebreos, por su parte, si es la providencia la referencia. Dios -y David en representación de éste- es pastor del pueblo. Poder que, definiendo esta cultura, la hace diferente de la griega, según Foucault, en algunos aspectos:

1) "El pastor ejerce el poder sobre un rebaño más que sobre una tierra" (Foucault, 1999, p. 100). Comenta Foucault, que las divinidades griegas poseían la tierra y no al pueblo, en cambio en los hebreos Dios dirige al rebaño y promete la tierra.

2) “El pastor agrupa, guía y conduce a su rebaño” (Foucault, 1999, p. 101). El jefe político en Grecia antigua, como vimos, tenía la función de organizar y mantener la unidad de la polis, pero no dependía el pueblo directamente de él. Sin él, sigue existiendo el pueblo. En el caso hebreo el rebaño se dispersa ante la ausencia del pastor.

3) "El papel del pastor consiste en asegurar la salvación de su rebaño" (Foucault, 1999, p. 101). Si bien los griegos sostenían que la divinidad salvaba la ciudad, este amparo no era directo, al dios griego se le pedía tierra y buena cosecha, en cambio en los hebreos, el pastor, Dios y David, atiende la necesidad individualmente, además de conducir, él mismo, a su rebaño hacia el mejor pasto.

4) “(...) El ejercicio del poder es un deber. (...) todo lo que hace el pastor lo hace por el bien de su rebaño" (Foucault, 1999, p. 102). comenta aquí Foucault, que entre los griegos, aunque el jefe político tenía que responder y decidir por el bien de su ciudad, su ejercicio era glorioso, ganara o no la guerra, la inmortalidad estaba garantizada, lo que no es el caso de los hebreos donde la función del pastor va de la mano con la abnegación: todo su hacer es por el bien de los otros.

Con el cristianismo evoluciona esta técnica de poder, a niveles insospechados por las dos culturas anteriores, opina el autor francés, adquiriendo al menos tres particularidades:

1. “(...) El pastor debe poder dar cuenta, no sólo de cada una de las ovejas, sino de todas sus acciones, de todo el bien o el mal que son capaces de hacer, de todo lo que les ocurre" (Foucault, 1990, p. 112). En otras palabras, el pastor, es responsable -y culpable- de cada uno de los movimientos que puedan hacer todos y cada uno de los participantes del colectivo que él dirige. 
el poder desde la perspectiva de foucault y la práctica de filosofía con niños en la escuela.

2. Se concibe "(...) la relación entre el pastor y sus ovejas como una relación de dependencia individual y completa" (Foucault, 1990, p.113). El rebaño depende de la voluntad de otro individuo, no de la ley o la razón. En este sentido, en el cristianismo, continúa Foucault, "La obediencia es una virtud" (1990, p.113). La sumisión por sí, ante el otro, adquiere un carácter positivo, es el objetivo.

3. Se supone “(..) una forma de conocimiento particular entre el pastor $y$ cada una de las ovejas. Este conocimiento es particular. Individualiza" (Foucault, 1990, p. 115). El pastor tiene que conocer al rebaño en su conjunto y a cada una de sus ovejas; debe saber y poder resolver sus necesidades. Para que el pastor cumpliera eficazmente esta función, comenta el autor, el cristianismo tomó del helenismo dos herramientas: el examen de conciencia y la dirección de conciencia. El primero una forma de contabilizar el bien y el mal realizado por el individuo, el otro marcado por consejos dados por el pastor ante los momentos difíciles (Foucault, 1999).

4. El pastor, por último, tiene que "conseguir que los individuos lleven a cabo su propia mortificación en este mundo. La mortificación no es la muerte, claro está, pero es una renuncia al mundo y a uno mismo: una especie de muerte diaria" (Foucault, 1990, p. 116). Tiene como función el pastor, siguiendo la cita, hacer que sus subordinados controlen el cuerpo y su voluntad sacrificándose cada día por la salvación futura.

De este modo dice Foucault que el cristianismo agrega al poder algunos matices que hacen de él:

Un juego extraño cuyos elementos son la vida, la muerte, la verdad, la obediencia, los individuos, la identidad; un juego que parece no tener ninguna relación con el de la ciudad que sobrevive a través del sacrificio de ciudadanos. Nuestras sociedades han demostrado ser realmente demoníacas en el sentido que asociaron estos dos juegos -el de la ciudad y el del ciudadano y el del pastor y el del rebaño en eso que llamamos estados modernos (Foucault, 1990, p. 117).

La crítica foucaultiana es feroz en este aspecto. Muestra cómo los vínculos entre humanos en la sociedad moderna se sustentaban en una relación vertical, de sumisión y filiación a la voluntad del otro, de Dios, de una verdad. Colocando una delgada línea entre la verdad y la mentira, la vida y la muerte, la salvación y la 
perdición a la que el hombre queda sujeto. Desde ella y en nombre del bien se justifica la agresión y la conquista.

Los estados modernos, según Foucault, ya no buscan la salvación en otro mundo, pero sí la pretenden encontrar en este mundo terrenal. "En este contexto entonces, la palabra salvación toma significados diferentes: salud, bienestar (riqueza suficiente, nivel de vida) seguridad y protección contra accidentes" (Foucault, 1982, p. 5). Con el objetivo de resguardar la suerte de los ciudadanos se establecen puntos de control como las delegaciones de policías, hospitales, escuelas, que garantizan la normalidad de la ocurrencia de las situaciones cotidianas, apartando al niño del adulto, el enfermo del sano, al loco del cuerdo, el delincuente del no-delincuente.

\section{el poder pastoral y la figura docente-alumno}

Nos parece interesante y complejo este análisis foucaultiano, pero con miras en los objetivos propuestos, nos referiremos aquí, no al estado en general, sino a la que afirma Walter Kohan (2004) como una de las figuras privilegiadas en la adopción del poder pastoral por el estado moderno, la figura docente-alumno.

Él -docente- asume la responsabilidad por las acciones y el destino de su grupo y de cada uno de sus integrantes. Él se encarga del bien y del mal que pueda suceder dentro del salón de clase. Él responde por todos los pecados que puedan ser cometidos en "su" espacio. Aunque adquiera modalidades leves y participativas, entre el docente y su grupo hay una relación de sometimiento absoluta; sin el docente, los alumnos no sabrían qué hacer, cómo aprender, de qué manera comportarse; ellos no sabrían lo que está bien y lo que está mal, cómo juzgar la actitud de un colega, la falta de esfuerzo de sí mismo para cumplir una tarea (Kohan, 2004, p. 100).

La imagen del maestro como pastor parece seguir vigente. Si bien, existen otras formas de ser maestro, la figura del maestro es comúnmente asociada a aquel que tiene que responder por cada uno de sus alumnos, conducirlos, guiarlos, alejarlos del mal, acercarlos al bien. Los alumnos, así, no son responsables de sus acciones y consecuencias. El docente, aquí, es el responsable y garante del destino de sus estudiantes. De igual modo,

Para desempeñar adecuadamente su trabajo, el docente necesita conocer el máximo posible de sus alumnos; hará diagnósticos de sus emociones, capacidades e inteligencias; conversará con sus 
el poder desde la perspectiva de foucault y la práctica de filosofía con niños en la escuela.

padres para saber detalles iluminadores de su pasado y de su presente; ganará la confianza de cada alumno para que le confíen sus deseos, angustias e ilusiones. Por último, le enseñará que sin alguna forma de sacrificio o renuncia de sí y del mundo, será imposible disfrutar de una vida feliz y de una sociedad justa (Kohan, 2004, p. 101).

Cuando la relación docente-alumno está marcada por la impronta del poder pastoral, se le suele enseñar al alumno a domar sus deseos y voluntades en pro de un bienestar futuro. Se le investiga, registrando sus acciones tanto en casa como en la escuela, con la finalidad de poder guiarlo individualmente de un modo eficiente.

Con esto, señala Kohan "no se trata de hacer al docente villano de la historia. Él también es en muchos sentidos rebaño, de los orientadores, consejeros, y directores que, por su parte son también rebaño de los administradores, supervisores, y macrogestores" (2004, p. 101). El docente y cada uno de las personas que participan de la institución hacen parte de una codificada red relacional, marcada por el poder pastoral.

Estamos de acuerdo con lo planteado por Kohan, consideramos con él que la relación docente-alumno suele mantener -aún hoy- la impronta cristiana. Lo que queremos agregar es un rasgo del pastoreo en los hebreos: la idea del ejercicio del poder como deber. Existen docentes, pensamos, que pueden asumir el ejercicio de sus funciones como un deber; cuidan, protegen, guían, conducen a sus alumnos por el buen camino, en cumplimiento de sus obligaciones. Lo que puede hacer con que estos docentes se vean sumergidos en un proceso anti-reflexivo en el que reproducen un conjunto de parámetros previamente establecidos.

Asimismo, queremos enfocar lo limitado que está el poder del alumno, dentro de una metáfora donde él es parte de un conjunto de ovejas. El alumno adquiere carácter animal -no sapiente-, mientras que el docente es un hombre. En vista de su categoría, el alumno se ve condicionado a seguir obedientemente la guía del docente.

Esta marcada relación pastoral dentro de la escuela es sofisticada por medio de una tecnología de poder que Foucault define como característica de la modernidad: El poder disciplinario. 


\section{el poder disciplinario y la escuela}

El uso cotidiano de la palabra disciplina dentro de la escuela, nos remite simultáneamente, como señala López, “(...) a la idea de distribución de saberes (disciplinas académicas) y a la del control de cuerpos, ejercicio de poder (disciplina de los alumnos en el aula)" (2008, p. 76). Ambas significaciones, la de un pensum (plan de estudio) meticulosamente dividido según el cual se fracciona el tiempo en la escuela y la de alumnos que siguen la norma, nos aproximan a la tecnología de poder descrita por Michel Foucault.

El capítulo III, de Vigilar y castigar, es denominado por su autor: Disciplina. Esta sección se inicia con una apología al cuerpo del militar, a su vigor, su valentía, su altivez, que se reconoce desde lejos. Esta alegoría al cuerpo no es casual. Es el objeto que la disciplina quiere controlar 5 .

En la disciplina el cuerpo se presenta, según Foucault, como objeto y blanco de poder. El cuerpo dócil “(...) que puede ser sometido, que puede ser utilizado, que puede ser transformado y perfeccionado" (2009, p. 159). El cuerpo es el territorio a ser conquistado.

Pero el cuerpo históricamente ha sido objeto de poder, ya ha pasado por el suplicio siendo apedreado públicamente ante un acto inmoral cometido; ha sido abatido con el látigo del amo sobre el esclavo. ¿Qué tiene entonces de diferente la disciplina y su pretendida docilidad de los cuerpos?

Existen tres características fundamentales, dirá Foucault, de la disciplina:

En primer lugar, la escala de control: no estamos en el caso de tratar el cuerpo, en masas, en líneas generales como si fuera una unidad indisociable, sino de trabajarlo en sus partes, de ejercer sobre él una coerción débil, de asegurar presas en el nivel mismo de la mecánica: movimientos, gestos, actitudes, rapidez, poder infinitesimal sobre el cuerpo activo (1975, p. 159).

\footnotetext{
${ }^{5}$ Foucault en su libro Vigilar y castigar, va construyendo el nacimiento de la prisión. Suplicio, Castigo, Disciplina y Prisión son los capítulos a través de los cuales va desarrollando las variaciones de los sistemas punitivos en nuestra sociedad. A partir de ellos se permite sentar una tesis general, la de una cierta “(... 'economía política' del cuerpo: incluso si no apelan a castigos violentos o sangrientos, incluso cuando utilizan los métodos 'suaves' que encierran o corrigen, siempre es del cuerpo del que se trata - del cuerpo y de sus fuerzas, de su utilidad y de su docilidad, de su distribución y de su sumisión" (Foucault, 2009, p.34). Sea el cuerpo desmembrado por caballos en el momento del suplicio, o el cuerpo encarcelado y corregido de un modo más "humano" en la prisión, el cuerpo es el eje central, de la historia de los sistemas punitivos, desde la perspectiva foucaultiana.
} 
el poder desde la perspectiva de foucault y la práctica de filosofía con niños en la escuela.

Los cuerpos son individualizados y tratados analíticamente. Todas sus partes son segmentadas y controladas para alcanzar su máximo provecho. El cuerpo del soldado se presenta sin defectos. Alto, esbelto y erguido. Uñas limpias, cabello con corte adecuado, uniforme impecable y botas lustradas. El sujeto importa en tanto esté sujetado al modelo establecido.

Esto nos lleva a la segunda característica, el objeto de control, donde lo que se quiere es vigilar permanentemente “(...) la economía, la eficacia de los movimientos, su organización interna; la coacción sobre las fuerzas más que sobre los signos; la única ceremonia que importa realmente es la del ejercicio" (Foucault, 2009, p. 159). Al estar el cuerpo controlado, el poder del individuo también. La finalidad del control va dirigida a la productividad de los movimientos del cuerpo para que éstos respondan a la institución establecida.

Los espacios donde la disciplina habita cuentan con un tercer elemento: la modalidad que implica “(...) una coerción ininterrumpida, constante, que vela por los procesos de la actividad más que por su resultado y se ejerce según una codificación que retícula con la mayor aproximación el tiempo, el espacio y los movimientos" (Foucault, 2009, p. 159).

En la escuela, por ejemplo, el alumno aprende a responder a los timbres que le marcan el tiempo, el espacio y sus movimientos. Lo escucha y va al aula a estudiar matemática, sabe que no podrá jugar, hasta el próximo timbre que le indique la hora de recreo, y después de unos minutos un mismo sonido acabará con su momento de esparcimiento, regresándolo de nuevo al aula. En este sentido, plantea Foucault, el resultado de cada actividad parece no importar porque el foco se coloca en la obediencia del alumno a la disciplina.

Todos estos métodos continúa el autor francés “(...) permiten el control minucioso de las operaciones del cuerpo, que garantizan la sujeción constante de sus fuerzas y les imponen una relación de docilidad-utilidad es a lo que se puede llamar disciplinas" (Foucault, 2009, p. 159). Se puede decir entonces que las disciplinas son el conjunto de técnicas que sujetan al cuerpo a un orden y procedimiento a un seguir determinado. El resultado es el control, la obediencia que permite extraer de él su máximo beneficio. 
La disciplina vista así, son formas generales de dominación,

Distintas de la esclavitud, -continua Foucault- puesto que no se fundan sobre una relación de apropiación de los cuerpos (...). Distintas también de la servidumbre, que es una relación de dominación constante, global, masiva, no analítica, ilimitada y establecidas bajo la forma de voluntad singular del amo (...). Distintas del vasallaje, que es una relación de sumisión extremadamente codificada, pero lejana, y que atañe menos a las operaciones del cuerpo que a los productos del trabajo y a las marcas rituales del vasallaje. Distintas también del ascetismo y de las disciplinas en tiempos monásticos, que tienen por función garantizar renuncias más que aumento de utilidad y que si bien implican obedecer a otro, tienen por objeto principal un aumento del dominio de uno sobre el cuerpo del otro (2008, p. 160).

De lo dicho por Foucault se desprende que en la disciplina el cuerpo es tratado de un modo más "suave", en el sentido que no está bajo la propiedad o voluntad de otro, ni es brutalmente golpeado. Es una tecnología característica del siglo XIX, que busca el modo más eficiente de ejercer su poder,

(..)un poder que, en lugar de sacar y retirar, tiene como función principal "enderezar conductas", o sin duda, hacerlo para poder retirar mejor y sacar más. No encadena las fuerzas para reducirlas; lo hace de manera que a la vez pueda multiplicarlas y usarlas (Foucault, 2009, p. 199).

Para cumplir con la función expresada por este filósofo, la de controlar y extraer de la suma de los cuerpos su máxima utilidad, se hace uso de tres simples instrumentos: (1) la vigilancia jerarquizada, (2) la sanción normalizadora, y (3) el examen (Foucault, 2009). Como veremos, si bien estos instrumentos se aplican sobre la totalidad del individuo, no tienen la necesidad de tocar físicamente el cuerpo.

(1) La vigilancia jerarquizada -dirá Foucault- es un juego de miradas que constriñen. “Un aparato en el que las técnicas que permiten ver inducen efectos de poder y donde, a cambio, los medios de coerción hacen claramente visible aquellos sobre los que se aplican" (2009, p. 200). La idea que habita el sistema disciplinario es la fiscalización de todos los movimientos que realicen los individuos, ejercer el poder con la mirada o sin la mirada: video, fotos, redes sociales en su conjunto, el panóptico.

La imagen que nos puede dibujar esto, es tal vez, aquellos pupitres uno detrás de otro, cinco filas, dispuestos todos con vistas a un punto central, que como Foucault dice “(...) sería a la vez fuente de luz que ilumina todo y lugar de 
el poder desde la perspectiva de foucault y la práctica de filosofía con niños en la escuela.

convergencia para todo lo que debe ser sabido: ojo perfecto al cual nada se sustrae y centro hacia el cual están vueltas todas las miradas" (2009, p. 203). Es al maestro a quién están viendo los alumnos, aquel que se presenta como modelo a seguir, portador de conocimientos, y que desde esa posición puede fichar, controlar, vigilar, fiscalizar el comportamiento de cada uno de sus alumnos.

(2) La sanción normalizadora, la segunda herramienta que facilita la disciplina, es aquel micro mecanismo penal que dicta la norma de estos centros de encierro (Foucault, 2009). En ellos se "goza de ciertos privilegios de justicia, con sus propias leyes, sus delitos especificados, sus formas particulares de sanción, sus instancias de juicio" (Foucault, 2009, p. 208).

Son mecanismos particulares de control, que más allá de las leyes y códigos del Estado, instituyen en ese espacio-tiempo lo que tiene que ser o no penalizado. Al sujeto quebrar la norma, es castigado. Para ello, continúa Foucault (2009) el castigo se constituye dentro de la disciplina desde un sistema doble: gratificaciónsanción.

Podemos ver plasmadas estas ideas de Foucault en la escuela. Allí existen normas claras. Por ejemplo, en algunas instituciones los alumnos no pueden llevar el cabello largo y las alumnas las faldas por encima de la rodilla. Fuera del recinto escolar esta norma no tiene ningún tipo de validez. Pero dentro, de no ser cumplida la norma, los alumnos serán sancionados; por el contrario, si obedecen la regla establecida serán gratificados.

Estos pequeños sistemas penales teniendo como función encausar la conducta de los cuerpos, homogenizan. Pero también, individualizan, estableciendo grados y rangos que permiten “(...) señalar las desviaciones, jerarquizar las cualidades, las competencias y las aptitudes y también castigar y recompensar" (Foucault, 2008, p. 210). Los alumnos, llevando esto a la escuela, son uniformados. A través de las reglas se busca que todos tengan el mismo comportamiento, sean clasificados en escala de valor y se mantengan las diferencias entre ellos. Nos topamos así, con buenos o malos estudiantes, los que cumplen la norma y los que no. 
(3) El examen: es la suma de las dos técnicas anteriores: vigilancia jerarquizada y sanción normalizadora. En la evaluación se conjugan la mirada que controla y la norma en función de la cual se clasifica y califica. Ésta es la razón, escribe Foucault, de que “(...) en todos los dispositivos disciplinarios, el examen se encuentre altamente ritualizado. En él vienen a unirse la ceremonia del poder y la forma de la experiencia, el despliegue de las fuerzas y el establecimiento de la verdad" (Foucault, 2009, p. 215).

En otras palabras, para Foucault, el examen es la máxima conmemoración del poder. El sujeto está ahí vivenciando la fuerza del otro que se erige como superior. El evaluado, sí quiere gozar de la gratificación, está limitado a comportase y responder adecuadamente, por el contrario, será sancionado.

Aunada a estas tres herramientas -vigilancia, sanción normalizadora y examen- se encuentra la arquitectura de estos centros de encierro donde se desenvuelve el poder disciplinario. Foucault (2009) en este sentido, hará referencia al panóptico de Bentham una estructura diseñada en 1791, centrada en el principio de que el poder debería ser visible e inverificable.

Visible: el detenido tendrá sin cesar ante los ojos la elevada silueta de la torre central desde donde es espiado. Inverificable: el detenido no debe saber jamás si en aquel momento se lo mira, pero debe estar seguro de que siempre puede ser mirado (Foucault, 2009, p. 233).

Son dos elementos, expresa este filósofo, con los que tendría que contar la estructura. Por un lado, el individuo siempre se debería sentir vigilado, por el otro, no podría corroborar, de ningún modo, si su sensación es un asunto de percepción o realidad.

Para alcanzar esto, la estructura presentada por Bentham, describe Foucault (2009), contaría con una torre central, desde la cual todos los sujetos podrían ser y sentirse vigilados. El vigilante no podría ser visto gracias a un juego de sombras que imposibilitaría saber si éste se encuentra o no en su lugar de trabajo. De tal modo, que la construcción garantizaría, que el individuo se supiese y sintiese, siempre vigilado, estándolo o no realmente. Es éste el efecto mayor del panóptico:

(...) inducir en el detenido un estado consciente y permanente de visibilidad que garantiza el funcionamiento automático del poder. Hacer que la vigilancia sea permanente en sus efectos, incluso si es discontinua en su acción. Que la perfección del poder tienda a volver 
el poder desde la perspectiva de foucault y la práctica de filosofía con niños en la escuela.

inútil la actualidad de su ejercicio; Que este aparato arquitectónico sea una máquina de crear y de sostener una relación de poder independiente de aquel que lo ejerce; en suma, que los detenidos se hallen insertos en una situación de poder de la que ellos mismos son los portadores (Foucault, 2009, p. 233).

De las palabras de este autor podemos decir entonces, que la función del panóptico no sería tan sólo controlar al individuo que está dentro, sino que el mismo individuo reproduzca el control; que la disciplina no se halle en una relación de exterioridad con respecto a él sino que lo habite. En este sentido, el poder disciplinario en el panóptico llegaría a su máxima expresión de perfección luciéndose como un poder poco costoso y altamente eficiente (Foucault, 2009).

\section{el poder y su resistencia}

Lo más interesante de todo esto es que el panóptico como una máquina perfecta nunca fue construido. Así lo señala Revel (2006), siguiendo a una entrevista realizada a Foucault (1978). En esa entrevista Foucault dice que el panóptico fue una utopía que nunca funcionó de la forma como fue imaginada. Esto hace pensar a esta autora:

(...) Que las relaciones de poder nunca alcanzan esa transparencia absoluta de la vida y de los cuerpos bajo los ojos del poder; en otros términos, esto significa que jamás la libertad de los hombres, lo opaco de sus relaciones, la complejidad de sus cambios, la riqueza de su vida, puede ser reducida bajo el dominio loco y total de aquello que pretende, al mismo tiempo, corregirla, gerenciarla y explotarla. ${ }^{6}$ (Revel, 2008, p. 60)

Aunque aún hoy podamos encontrar alguna de las características del sueño de Bentham, en la arquitectura de las escuelas, hospitales, prisiones y manicomios, como esa idea de un patio central desde donde se puede vigilar a todos los individuos, estos lugares no pueden, como lo señala la cita, encerrar la multiplicidad humana, las personas que habitan estos espacios, lo dinamizan haciendo imposible la idea de una entidad rígida que los coaccione por entero.

\footnotetext{
6 “(...) Que as relações de poderes nunca alcançam essa transparência absoluta da vida e dos corpos sob o olho do poder; em outros termos, isto significa que jamais a liberdade dos homens, a opacidade de suas relações, a complexidade de suas trocas, a riqueza de sua vida pode ser reduzida sob o domínio louco e total de aquilo que pretende, ao mesmo tempo, corrigi-la, gerenciá-la e explorá-la" (Revel, 2006, pág.60). (Traducción propia)
} 
Ante esa fuerza que intenta, como dice Revel, gerenciar, corregir, conquistar al sujeto, se hace presente el hombre en su complejidad, ser vivo, que desde su vitalidad se rehúsa a ser asesinado, con la poca movilidad que implica estar bajo el mando de una estructura. El poder que se ejerce sobre el otro, trae consigo, de este modo, la resistencia.

La resistencia en Foucault, como señala Giraldo (2006) “(...) no es una sustancia y no es anterior al poder, es coextensiva al poder, tan móvil, tan inventiva y tan productiva como él (...)” (p. 106). La resistencia es inmanente al poder, por eso sus definiciones van de la mano:

Así como la red de las relaciones de poder concluyen por construir un espacio tejido que atraviesa aparatos y los instrumentos sin localizarse exactamente en ellos, así también la formación del enjambre de puntos de resistencia surca las estratificaciones sociales y las unidades individuales, y es sin duda la codificación estratégica de esos puntos de resistencia lo que torna posible una revolución (Foucault, 2006, p. 102).

La resistencia consiste en relaciones de fuerzas multiformes, que quiebran, cortan, fracturan el poder. La resistencia son líneas de convergencia que inciden en los alineamientos coercitivos que pretende efectuar el poder disciplinario. Circulando entre nosotros, en lo cotidiano, están las líneas de poder y resistencia. Están atadas una con la otra.

En este sentido entendemos que, para Foucault, la revolución no es la toma de poder, porque como él mismo dice, éste no se puede agarrar. Es más bien, la conjunción articulada de puntos de resistencia. Puntos que expresando su multiplicidad se niegan a la normalización establecida.

Un punto de resistencia pensamos, a partir de lo propuesto, puede ser la decisión de un alumno de no hacer su tarea. Él, desde su no hacer, ejerce su libertad, corta el poder, lo modifica, ¿Dónde queda ahí el supuesto poder del maestro? ¿De la escuela sobre él? ¿En la calificación y clasificación posterior de este alumno?

Sí todos los alumnos decidiesen, ejercer su libertad y no hacer su tarea, en la articulación de sus resistencias individuales, estaría la posibilidad de una revolución. Esta resistencia articulada no pasa por tomar o quitarle el aparente poder al maestro o director, sino por expresar la insatisfacción, sacudir las redes de poder, y abrir espacio a la complejidad humana. 
el poder desde la perspectiva de foucault y la práctica de filosofía con niños en la escuela.

Foucault muestra cómo el sistema escolar que ha permitido la educación masiva de niños, se articula desde un método que tiende a ser coercitivo, haciendo dóciles los cuerpos y extrayendo de ellos su máxima utilidad. Donde aún hoy, se puede reconocer la vigilancia jerarquizada, la sanción normalizadora y el examen, herramientas a través de las cuales, como fue descrito, se ejerce el poder disciplinario. Pero en la cual, se presentan a su vez diversos y creativos puntos de resistencia.

\section{filosofía con niños: ¡resistencia!}

Al leer los libros en que Walter Kohan expone la experiencia de filosofía con niños nos encontramos repetidas veces con la alusión a Michel Foucault. El sísmico ${ }^{7}$ filósofo francés que sacude, línea a línea, la racionalidad en la que se levanta el edificio del Estado moderno, entendemos, le permitió -y le permite, entre otras cosas-, al autor pensar las relaciones de poder a través de las cuales se mediatiza su práctica, a lo que él en tanto docente y los niños en tanto alumnos están sujetos.

Walter Kohan reconoce el complejo carácter disciplinario de la escuela, como lo hemos desarrollado. Por eso nos hemos acercado a Foucault. En las escuelas, dice el autor,

(...) los individuos tienen experiencias de sí que modifican la relación consigo mismos en una dirección precisa. Son experiencias demarcadas por reglas y procedimientos que incitan subjetividades dóciles, disciplinadas y obedientes. La escuela moderna no es hospitalaria de la libertad aunque precise de ella para que lo que acoge sea ejercicio del poder disciplinario de sus visitantes y no de un mero sometimiento (Kohan, 2004, p. 103).

El individuo que se acepta como normal dentro de la escuela, destaca Kohan, siguiendo a Foucault, es aquél que tiene la virtud de seguir las reglas y la voluntad de otro. Sumiso. Aquel sujeto, que tiene que emitir la idea recibida, porque aunque puede elegir no hacerlo, conoce bien las consecuencias dentro del sistema de su irreverencia.

Ante esto, escribe Kohan,

Pensamos en una filosofía que permita poner en cuestión el modo dominante de constitución de la subjetividad escolar: para ello, es

\footnotetext{
${ }^{7}$ Apelativo utilizado por Guilles Deleuze para referirse a su amigo Michel Foucault, en su libro Conversaciones (1977).
} 
preciso una filosofía que indiscipline, que se oponga al disciplinamiento escolar, que ayude a pensar preguntas tales como: ¿Es posible una escuela/ educación no disciplinar? ¿Podemos inventar una institución (y una sociedad) donde se ejerza el poder de forma menos jerárquica, autoritaria y discriminadora? ¿Es posible educar subjetividades más libres, imprevisibles, menos disciplinadas? (Kohan, 2004, p. 116).

Lo que el ser humano es, está sujeto a la red de relaciones de poder de la cual es parte. La filosofía, siguiendo la cita, siendo praxis cuestionadora, permite reflexionar el campo de acción, ponerlo en juego, abrirlo. Ante una única realidad, dibuja signos de interrogación, que les permite a los practicantes pensar en otras posibilidades. El docente que práctica filosofía con niños, se resiste aceptar una única realidad, a cualquier forma de imposición, como dice más una vez, Kohan y Waskman (2005):

Resistimos a la unidimensionalidad de la globalización, la omnipotencia del mercado, porque imponen una lógica que avasalla nuestra autonomía, porque pretenden decidir por nosotros. Resistimos esa lógica porque nos vuelve menos humanos, limita nuestra práctica y nuestro pensar, restringe nuestra libertad de pensar y ser lo que queremos ser (p. 78).

Kohan plantea una filosofía dentro del recinto escolar como una práctica de diálogo donde los individuos puedan pensar los mecanismos a los que se encuentran atados, haciendo posible que a través de la permanente reflexión puedan ser aquello que quieren ser. Es ésta la libertad foucaultiana de la que hablamos, tener la posibilidad de imaginar y vivir otra opción. En este sentido la filosofía dentro de la escuela es resistencia.

Siendo ésta la función de la filosofía, no se justifica qué sea ella un privilegio, ¿hay alguna persona -niño o adulto- que no tenga el derecho a pensar lo que es y quiere ser más allá de lo que se le exige ser? De este modo, Kohan (2003) defiende la posibilidad de hacer Filosofía con Niños, “No para que sean filósofos profesionales, pero sí para que ellos sean capaces de articular por sí mismos la visión de mundo que nortea su vida en sociedad"8 (Kohan, 2003, p. 12).

\footnotetext{
8 "Não para que sejam filósofos profissionais, mas sim para que eles sejam capazes de articular por si mesmos a visão do mundo que norteia sua vida em sociedade" (Kohan, 2003, p.12) (Traducción propia).
} 
el poder desde la perspectiva de foucault y la práctica de filosofía con niños en la escuela.

Por esto Kohan, buscando un espacio de inclusión, acude a la escuela pública, siendo lo público,

(...) el espacio común, aquel que no está sometido a intereses particulares ni a las leyes del mercado. Es el espacio de la lucha política, lucha por la apropiación de un espacio privilegiado para la legitimación de y circulación de saberes, y para la constitución de la subjetividad. Es al mismo tiempo, un espacio de pretensiones universales, que por definición ansía poder recibir a todos, sin cobrar entrada. Por último, es el espacio de las clases excluidas, de aquellas que no pueden pagar más de lo que ya pagan por su educación. Aquellos que más sufren el precio de la socialización sin haber hecho nada para eso 9 (Kohan, 2003, p. 13).

Kohan piensa en la escuela pública como un espacio de alto alcance para la normalización de saberes porque es un espacio abierto a todos, también para aquellos históricamente excluidos. La filosofía dentro de este recinto, podría colocar en cuestión el juego de lo normal y ser compartida, como en tiempos de Sócrates en plazas públicas, con más y más personas.

Finalmente, entendemos que el docente que desarrolla la práctica de filosofía con niños, propuesta por Kohan, está dispuesto, en diálogo con los niños, a cuestionarse qué es en cuanto docente, alumno, seres humanos y si quiere continuar siendo eso que es. De ser así, la filosofía, puede posibilitarnos a los docentes, imaginar y realizarnos de otras formas. De cuestionarnos, por ejemplo, los instrumentos del poder disciplinario presentados por Foucault, como vimos, la vigilancia jerarquizada, la sanción normalizadora, y el examen. ¿Qué significados tiene para mis alumnos mi "mirada" docente? ¿Qué significados tiene su "mirada" alumno sobre mi que soy docente? ¿Qué llamamos de "mirada" de alumno"? ¿Qué llamamos de "mirada" docente? ¿Qué sanciones existen en la escuela? ¿Por qué existen? ¿Sería posible una escuela sin sanciones? ¿Por qué realizamos exámenes? ¿Cuál es el sentido que tienen esos exámenes? ¿Estoy de acuerdo con ese sentido?

\footnotetext{
${ }^{9}$ Entendemos o espaço público como o espaço comum, aquele que não está submetido a interesses particulares nem as leis do mercado. É o espaço da luta política, luta pela apropriação de um espaço privilegiado para a legitimação e circulação de saberes, e para a constituição de subjetividade. É, ao mesmo tempo, um espaço de pretensões universais, que por definição anseia poder receber a todos, sem cobrar ingresso. Por ultimo, é o espaço das classes excluídas, daqueles que não podem pagar mais do que já pagam pela sua educação, aqueles que mais sofrem o preço da socialização sem ter feito nada para isso" (Kohan, 2003, p. 13). (Trad. propia).
} 
¿Quiero continuar realizando exámenes? ¿Qué otros sentidos puede tener un examen?

\section{conclusiones}

El poder, siguiendo la idea foucaultiana, pretende determinar las posibles acciones de los individuos, restringir lo que los sujetos pueden o no. En este sentido, Foucault plantea entender el poder no en términos represivos, sino como un juego de fuerzas múltiples, móviles, no igualitarias que generan los sujetos en sus relaciones.

La palabra "sujeto", guarda un doble significado, sujetados al control y obediencia de otro individuo y sujetados a las prácticas sociales a través de las cuales se tiene conocimiento de sí.

La escuela, desde la perspectiva que aquí desarrollamos, puede ser un centro de encierro, similar a las cárceles, hospitales, manicomios, teniendo como objetivo enderezar las conductas, sustraer y multiplicar la fuerza de los individuos para alcanzar una mayor docilidad-utilidad; esto es denominado por Foucault: poder disciplinario. Este poder se vale de tres instrumentos: la vigilancia jerarquizada, la sanción normalizadora y el examen.

El poder disciplinario tiene la impronta del poder pastoral, que refiere a la analogía entre el pastor y la divinidad, rey o jefe. El maestro, tal cual pastor, tiende a responder por cada uno de sus alumnos, conducirlos, alejarlos del mal, acercarlos al bien. Se le enseña al alumno a domar sus deseos y voluntades, en pro de un bienestar futuro. Se le investiga, registrando sus acciones tanto en casa como en la escuela, con la finalidad de poder guiarlo individualmente de un modo eficiente.

La resistencia es inmanente al poder, son también relaciones multiformes, que quiebran, cortan, fracturan el poder; líneas de convergencias que inciden en los alineamientos coercitivos que efectúa el poder normalizador.

Para Walter Kohan este poder disciplinario nos torna seres sujetados por el control y la dependencia. Si queremos cambiar lo que somos, entonces tenemos que modificar los dispositivos que nos conforman. La filosofía, en cuanto pensar crítico $\mathrm{y}$ abierto, tiene que cuestionar el poder que nos coacciona. 
el poder desde la perspectiva de foucault y la práctica de filosofía con niños en la escuela.

La propuesta Filosofía con Niños, propuesta por Walter Kohan, busca abrir espacios de reflexión dentro de la escuela que permitan pensar los mecanismos a los que estamos sujetados, para ir trascendiendo, poco a poco, al paso del diálogo filosófico, la docilidad de los cuerpos. Para liberarnos y decidir por nosotros mismos y junto a otros, lo que somos y queremos ir siendo.

\section{referencias}

Castro, E. "Poder", en E. Castro. El vocabulario de Michel Foucault (p. 408- 424) 2004. Disponible en: http://es.scribd.com/doc/11414155/Castro-Edgardo-ElVocabulario-de-Mfoucault Acceso en: 10 de noviembre de 2011

Foucault, M. El orden del discurso. 1970 Disponible en: http:/ / fliiby.com/file/493809/12ju17b1et.html Acceso en: 05 de Junio de 2010.

Foucault, M. Microfísica del poder. Madrid: Las ediciones de la Piqueta, 1979.

Foucault, M. Tecnologías del yo. Barcelona: Paidós, 1990.

Foucault, M. “Dispositivo de sexualidad”, en Foucault, M. La Voluntad de saber. (p. 79-140) Madrid: Siglo XXI. 2006.

Foucault, M. Vigilar y castigar. México: Siglo XXI, 2009.

Giraldo, R. Poder y resistencia en Michel Foucault. Revista Tabula Rasa, n. 4 (113-122) 2006. Bogotá, Colombia. Disponible en: http://www.revistatabularasa.org/numero_cuatro/giraldo.pdf Acceso en: 15 de julio de 2011.

Guzmán, F. Michel Foucault: El Pensamiento de la Contingencia. Revista Observaciones

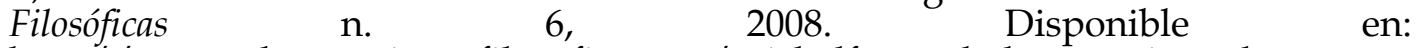
http://www.observacionesfilosoficas.net/michelfoucaultelpensamiento.htm . Acceso en: 1 de julio de 2011.

Kohan, W. "Lipman y la filosofía. Notas para pensar un concepto", en F. García. (2002). Matthew Lipman: Filosofía y Educación. (p. 49-70) Madrid: Ediciones de la Torre, 2002.

Kohan, W. Infancia entre Educación y Filosofía. Buenos Aires: Laertes, 2004.

Kohan, W; Waksman, V. Filosofía con Niños: Aportes para el Trabajo en Clase. Buenos Aires: Novedades Educativas, 2005.

Kohan, W. "Sobre los riesgos y posibilidades de la filosofía con niñ@s", en W. Kohan (comp.) (2006). Teoría y práctica en filosofía con niños y jóvenes. (p. 7-20) Buenos Aires: Novedades Educativas, 2006.

KohaN, W. Infancia, política y pensamiento. Ensayos de filosofía y educación. Buenos Aires: Del estante editorial, 2007.

Kohan, W. Pensando a práctica da filosofia na escola, 2003. Disponible en: http://egroups.unb.br/fe/tef/filoesco/fundamentos.html Acceso en: 10 de septiembre de 2010.

Kohan, W. Entrevista a Walter Kohan: Infancia, emancipación y filosofía. Por J. Almario y J. Galindo. Universidad Icesi, Cali, Colombia. 2010. Disponible en: http://www.icesi.edu.co/blogs/psicologia/2010/11/12/entrevista-a-walterkohan-infancia-emancipacion-y-filosofia/ Acceso en: 01 de febrero de 2010.

López, M. Filosofía con niños y jóvenes. Buenos Aires: Noveduc, 2008.

Morey, M. Prólogo. En G. Deleuze (1987). Foucault. (p. 11-23) Barcelona: Paidós, 1987.

Nuñez, M. Dispositivo y dominación en el modelo panóptico. 2002. Disponible en: http://antroposmoderno.com/antro-articulo.php?id_articulo=137\%20 Acceso en: Extraído 07 de julio de 2011.

Revel, J. "Nas origens do biopolítico: de vigiar e punir ao pensamento da atualidade", em: J. Gondra y W. Kohan (comp.) (2006). Foucault 80 anos. (p. 51-62) Belo Horizonte: Autêntica, 2006.

recibido en: 21.08 .2021

aprobado en: 30.11.2021 